\title{
The eIF2a serine 51 phosphorylation-ATF4 arm promotes HIPPO signaling and cell death under oxidative stress
}

\author{
Kamindla Rajesh ${ }^{1}$, Jothilatha Krishnamoorthy ${ }^{1, *}$, Jyotsana Gupta ${ }^{1, *}$, Urszula \\ Kazimierczak ${ }^{1,2}$, Andreas I. Papadakis ${ }^{1}$, Zhilin Deng ${ }^{1}$, Shuo Wang ${ }^{1}$, Shinji Kuninaka ${ }^{3}$ \\ and Antonis E. Koromilas ${ }^{1,4}$ \\ ${ }^{1}$ Lady Davis Institute for Medical Research, McGill University, Sir Mortimer B. Davis-Jewish General Hospital, Montreal, \\ Quebec, Canada \\ 2 Department of Cancer Immunology, Poznan University of Medical Sciences, Poznan, Poland \\ ${ }^{3}$ Division of Gene Regulation, Institute for Advanced Medical Research, Keio University School of Medicine, Tokyo, Japan \\ ${ }^{4}$ Department of Oncology, Faculty of Medicine, McGill University, Montreal, Quebec, Canada \\ * These authors have contributed equally to this study \\ Correspondence to: Antonis E. Koromilas, email: antonis.koromilas@mcgill.ca \\ Keywords: translation initiation factor elF2, protein phosphorylation, activating transcription factor 4, mRNA translation, large tumor \\ suppressor 1 \\ Received: June 16, 2016 \\ Accepted: June 23, 2016 \\ Published: July 07, 2016
}

\section{ABSTRACT}

The HIPPO pathway is an evolutionary conserved regulator of organ size that controls both cell proliferation and death. This pathway has an important role in mediating cell death in response to oxidative stress through the inactivation of Yes-associated protein (YAP) and inhibition of anti-oxidant gene expression. Cells exposed to oxidative stress induce the phosphorylation of the alpha (a) subunit of the translation initiation factor eIF2 at serine 51 (eIF2aP), a modification that leads to the general inhibition of mRNA translation initiation. Under these conditions, increased eIF2aP facilitates the mRNA translation of activating transcription factor 4 (ATF4), which mediates either cell survival and adaptation or cell death under conditions of severe stress. Herein, we demonstrate a functional connection between the HIPPO and eIF2aP-ATF4 pathways under oxidative stress. We demonstrate that ATF4 promotes the stabilization of the large tumor suppressor 1 (LATS1), which inactivates YAP by phosphorylation. ATF4 inhibits the expression of NEDD4.2 and WWP1 mRNAs under pro-oxidant conditions, which encode ubiquitin ligases mediating the proteasomal degradation of LATS1. Increased LATS1 stability is required for the induction of cell death under oxidative stress. Our data reveal a previously unidentified ATF4-dependent pathway in the induction of cell death under oxidative stress via the activation of LATS1 and HIPPO pathway.

\section{INTRODUCTION}

The HIPPO pathway is conserved from Drosophila to mammals and is involved in cell growth, proliferation, apoptosis, organ size and tumorigenesis [1]. It consists of two groups of kinases, the mammalian STE20-like protein kinase 1 (MST1) and MST2, and the large tumor suppressor 1 (LATS1) and LATS2, in combination with their activating adaptor proteins, Salvador family WW domain-containing protein 1 (SAV1) and MOB kinase activator 1 (MOB1), respectively [1]. The transcriptional module of the pathway is composed of the transcriptional co-activators yes-associated protein (YAP) and its paralogue, transcriptional co-activator with PDZ-binding motif (TAZ), and TEA domain family members (TEAD14). When the upstream kinase module is activated, LATS1 and LATS2 phosphorylate YAP/TAZ at multiple sites [2], which leads to inhibition of transcriptional activity through 14-3-3-mediated cytoplasmic retention of YAP/ TAZ and its proteasomal degradation [3]. When YAP/ TAZ is not phosphorylated by the LATS kinases, they translocate to the nucleus and bind to sequence specific transcription factors TEAD1-4 (and other transcription factors including SMAD, RUNX, TP73, FOXO1), which 
enables the transcription of genes involved in proliferation and survival [3].

Regulation of mRNA translation is one of the most immediate cell responses to any form of stress [4]. Cells respond to various stress forms by blocking the initiation process via the phosphorylation of eIF2 $\alpha$ at serine (S) 51 (herein referred to as eIF $2 \alpha \mathrm{P}$ ), a modification that leads to global inhibition of protein synthesis $[4,5]$. Induction of eIF $2 \alpha \mathrm{P}$ is mediated by a family of four kinases each of which is activated by different forms of stress and is part of a biological process known as the integrated stress response (ISR) [5, 6]. The family consists of the hemeregulated inhibitor (HRI) activated by heme-deficiency in erythrocytes; the protein kinase RNA-dependent kinase (PKR) activated by double stranded (ds) RNA and virus infection; the PKR-like endoplasmic reticulum (ER) resident kinase (PERK) activated by the accumulation of misfolded proteins in the ER; and the general control nonderepressible 2 (GCN2) activated by uncharged tRNAs from amino acid deprivation $[5,6]$. Increased eIF $2 \alpha \mathrm{P}$ leads to a global inhibition of mRNA translation but also facilitates translation of select mRNAs synthesizing proteins with key roles in adaptation to stress [7]. That is, mRNAs encoding for the activating transcription factor 4 (ATF4) and ATF5 in mammalian cells, or general control non-repressed 4 (GCN4) in yeast, are better translated under conditions of increased eIF $2 \alpha \mathrm{P}$ through delayed translation re-initiation from upstream open reading frames (uORFs) within the 5' untranslated region (5' UTR) [8-10].

Oxidative stress occurs when the equilibrium between cellular production of pro-oxidants and antioxidant defense mechanisms is disrupted leading to accumulation of reactive oxygen species (ROS), including the superoxide radical $\mathrm{O}_{2}{ }^{--}$, hydrogen peroxide $\mathrm{H}_{2} \mathrm{O}_{2}$, and the highly reactive hydroxyl radical $\mathrm{OH}$ [11]. Cells cope with ROS by increasing the expression of anti-oxidant genes and activating pathways that control survival and adaptation to oxidative stress [11]. The HIPPO pathway has been implicated in the induction of cell death under oxidative stress. Oxidative stress activates MST1 by disrupting its interaction with Thioredoxin-1 or by promoting its phosphorylation by c-ABL leading to the phosphorylation of the forkhead transcription factor FOXO3 and increased expression of the pro-apoptotic gene BIM in neuronal cells [12-14]. ROS production by ischaemia/reperfusion results in cardiomyocyte death via the activation of MST1 and inactivation of the YAP and FOXO3 transcriptional complex, which limits the expression of anti-oxidant genes and promotes oxidative stress-mediated cell death [15-17]. On the other hand, induction of eIF $2 \alpha \mathrm{P}$ plays a pivotal role in the regulation of redox homeostasis and adaptation of eukaryotic cells to oxidative stress [18-22]. eIF2 $\alpha \mathrm{P}$ decreases ROS production, prevents the appearance of premature senescence in primary fibroblasts and protects tumor cells from death caused by pro-oxidant drugs [19]. ATF4, which is efficiently translated under conditions of enhanced eIF $2 \alpha \mathrm{P}$, mediates the transcriptional induction of several genes encoding for proteins controlling anti-oxidant responses, amino acid import and protein synthesis, which contribute to either the adaptation of cells to oxidative stress or induction of death under excessive oxidative stress $[21,23]$. Herein, we demonstrate that the eIF2 $\alpha \mathrm{P}$ ATF4 arm activates the HIPPO pathway to promote death in response to oxidative stress. This is mediated by the ability of ATF4 to suppress the expression of E3 ubiquitin ligases that mediate the destabilization of LATS1 leading to increased HIPPO signaling and induction of oxidative cell death.

\section{RESULTS}

\section{Increased eIF2 $\alpha$ P facilitates LATS1 expression under oxidative stress}

We examined LATS1 expression and YAP phosphorylation in primary mouse embryonic fibroblasts as well as primary and immortalized human fibroblasts that were genetically engineered to be impaired in eIF $2 \alpha \mathrm{P}$ [19]. We observed that LATS1 protein was downregulated in primary mouse embryonic fibroblasts (MEFs) bearing a homozygous S51A allele of eIF2 $\alpha$ (eIF $2 \alpha \mathrm{A} / \mathrm{A})$ compared to primary MEFs with wild type eIF $2 \alpha$ allele (eIF $2 \alpha \mathrm{S} / \mathrm{S}$; Figure 1A) [19]. Decreased LATS1 was associated with decreased phosphorylation of YAP at S127, which is mediated by LATS1 and implicated in the inactivation of YAP [24]. Based on our previous study demonstrating that impaired eIF $2 \alpha \mathrm{P}$ in primary MEFs leads to increased ROS production [19], we examined whether ROS was responsible for LATS1 downregulation in eIF2 $\alpha \mathrm{A} / \mathrm{A}$ MEFs. Incubation of primary eIF $2 \alpha \mathrm{S} / \mathrm{S}$ and eIF $2 \alpha \mathrm{A} / \mathrm{A}$ MEFs with Trolox, which is a derivative of vitamin $\mathrm{E}$ with anti-oxidant function [25], prevented the downregulation of LATS1 and inhibition of YAP S127 phosphorylation in eIF $2 \alpha \mathrm{A} / \mathrm{A}$ MEFs compared to eIF $2 \alpha \mathrm{S} / \mathrm{S}$ MEFs (Figure $1 \mathrm{~B})$. These data suggested that loss of eIF $2 \alpha \mathrm{P}$ decreases the expression of LATS1 as a result of increased oxidative stress.

We also employed human IMR-90 and telomerase reverse transcriptase (TERT)-immortalized BJ (BJhTERT) fibroblasts, which were shown by our group to contain increased ROS under conditions of impaired eIF $2 \alpha \mathrm{P}$ [19]. The human fibroblasts were engineered to express an HA-tagged form of the non-phosphorylatable eIF2 $\alpha$ S51A mutant with dominant negative (DN) function (Figure 1C, 1D) [19]. The DN-expressing fibroblasts were further modified to be deficient in eIF $2 \alpha \mathrm{P}$ by the expression of a short-hairpin (sh) RNA against the 3' untranslated region of the endogenous eIF $2 \alpha$ mRNA 
[19]. This approach generated human fibroblasts predominantly expressing the non-phosphorylated HAeIF2 $\alpha$ S51A mutant, which are referred to as knock-in (KI) cells (Figure 1C, 1D). We noticed that IMR-90 and
BJ-hTERT KI fibroblasts exhibited decreased levels of LATS1 and YAP S127 phosphorylation compared to fibroblasts with intact eIF2 $\alpha$ (Figure 1C, 1D). Considering that inhibition of eIF $2 \alpha \mathrm{P}$ results in increased ROS in the
(A)

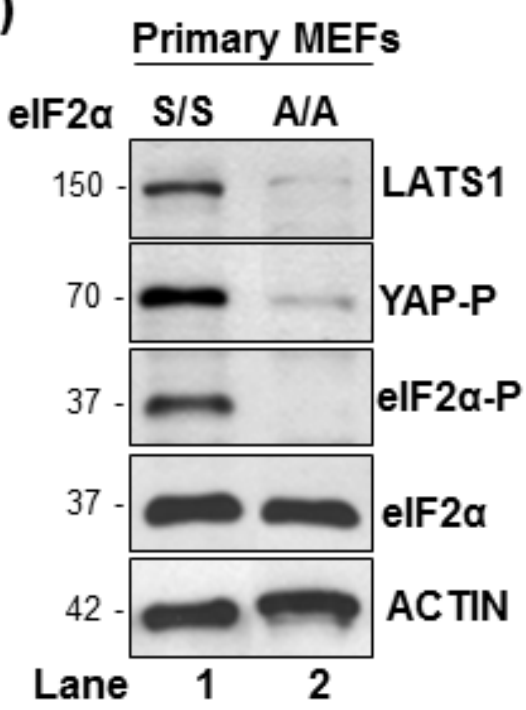

(B)

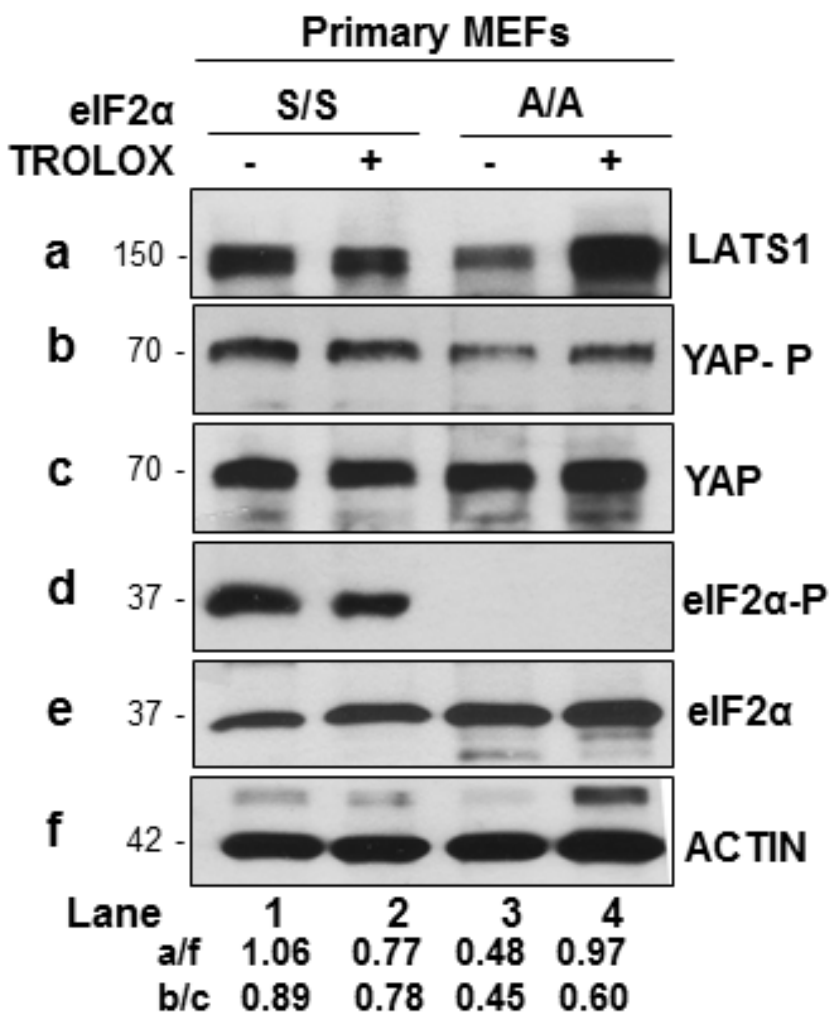

(D)

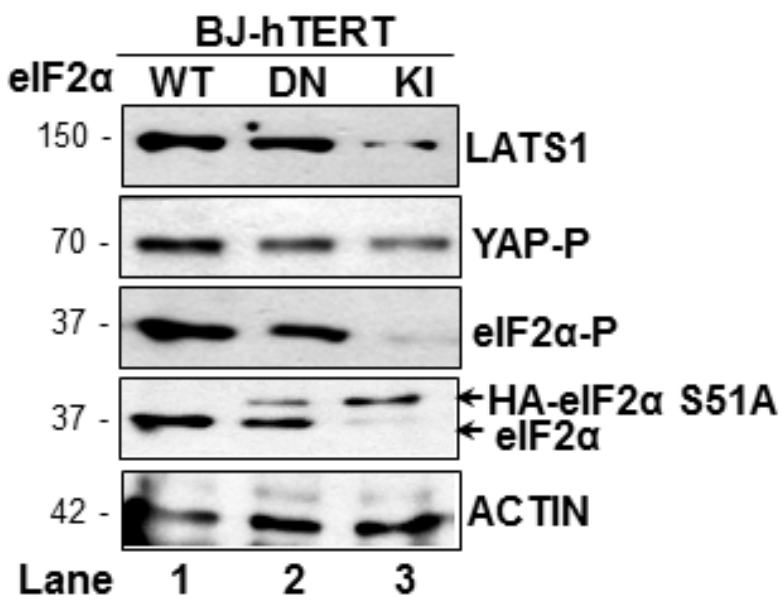

Figure 1: eIF2 $\alpha$ P promotes LATS1 expression in mouse and human fibroblasts. (A, B) Primary MEFs containing either wild type (S/S) or the S51A mutant eIF2 $\alpha$ allele (A/A) were left untreated A. or treated with $200 \mu$ M Trolox B.. C., D. Human IMR-90 C. and BJ-hTERT fibroblasts D. containing endogenous eIF2 $\alpha$ (wild type; WT; lane 1) or the non-phosphorylated dominant negative (DN) HAeIF2 $\alpha$ S51A in the absence (lane 2) or presence of shRNA targeting the 3' untranslated region (3' UTR) of endogenous eIF2 $\alpha$ (knock-in; KI; lane 3). A.-D. Protein extracts $(50 \mu \mathrm{g})$ were subjected to immunoblot analyses for the indicated proteins. The approximate molecular size of the proteins as well as the position of HA-eIF $2 \alpha$ S51A in the polyacrylamide gels compared to endogenous eIF2 $\alpha$ is indicated. eIF2 $\alpha$-P, S51 phosphorylation; YAP-P, S127 phosphorylation. 
human fibroblasts [19], the data indicated that LATS1 downregulation in eIF $2 \alpha \mathrm{P}$-deficient cells depends, at least in part, on ROS.

We previously demonstrated that tumor cells with impaired eIF $2 \alpha \mathrm{P}$ are adapted to increased intracellular ROS but become increasingly sensitive to the antiproliferative effects of extrinsic $\operatorname{ROS}[18,19]$. We observed that human lung tumor A549 cells and human fibrosarcoma HT1080 cells displayed increased eIF $2 \alpha \mathrm{P}$ and LATS1 in response to increasing concentrations of hydrogen peroxide $\left(\mathrm{H}_{2} \mathrm{O}_{2}\right)$ (Figure $\left.2 \mathrm{~A}, 2 \mathrm{~B}\right)$. On the other hand, LATS1 expression was downregulated by the $\mathrm{H}_{2} \mathrm{O}_{2}$ treatments in eIF2 $\alpha \mathrm{P}$-deficient A549 and HT1080 cells indicating that eIF $2 \alpha \mathrm{P}$ is required for LATS1 upregulation under oxidative stress. The ability of eIF $2 \alpha \mathrm{P}$ to promote LATS1 expression became further evident in experiments with the pro-oxidant drug phenylarsine oxide (PAO), which decreased LATS 1 in the eIF $2 \alpha \mathrm{P}$-deficient but not proficient HT1080 cells (Figure 2C) [18, 26].

\section{ATF4 mediates LATS1 stabilization under oxidative stress}

ATF4 plays a key role in mediating the biological effects of eIF $2 \alpha \mathrm{P}$ in response to oxidative stress [21, 27]. We employed immortalized MEFs that were either proficient (WT) or knockout (KO) of ATF4 as well as HT1080 cells, which were engineered to be deficient for ATF4 by shRNA expression [18]. In both cell types, ATF4 deficiency was confirmed by the immunoblotting of ATF4 protein in extracts from cells subjected to ER stress by thapsigargin (Figure 3A, 3B). When cells were exposed to $\mathrm{H}_{2} \mathrm{O}_{2}$, we noticed that LATS1 was upregulated in ATF4-proficient MEFs and HT1080 cells as opposed to ATF4-deficient cells in which LATS1 was downregulated with increasing concentrations of $\mathrm{H}_{2} \mathrm{O}_{2}$ (Figure 3C, 3D). A similar effect of ATF4 on LATS1 expression was observed in MEFs exposed to $\mathrm{H}_{2} \mathrm{O}_{2}$ for different time points (Figure 3E). We further noticed that induction of eIF $2 \alpha \mathrm{P}$ was proportional to the concentrations of $\mathrm{H}_{2} \mathrm{O}_{2}$ in ATF4-proficient MEFs and HT1080 cells (Figure 3C, 3D). However, ATF4-deficiency resulted in decreased eIF $2 \alpha \mathrm{P}$ in the mouse and human cells after $\mathrm{H}_{2} \mathrm{O}_{2}$ treatment compared to the isogenic control cells through as yet unclear mechanism (Figure 3C, 3D).

We further examined whether LATS1 was under the transcriptional control of ATF4. LATS1 mRNA levels did not significantly differ between ATF4-proficient and deficient HT1080 cells subjected to $\mathrm{H}_{2} \mathrm{O}_{2}$ treatment (Figure 4A). Under these conditions, induction of the DNA damage-inducible transcript 3, also known as $\mathrm{C} /$ EBP homologous protein $(C H O P)$, which is an ATF4dependent gene in stressed cells [23], was impaired in ATF4-deficient compared to proficient HT1080 cells treated with $\mathrm{H}_{2} \mathrm{O}_{2}$ (Figure 4A). Thus, ATF4 is unlikely to play a role in LATS1 expression at the transcriptional level. Because LATS1 expression is tightly controlled by post-translational modifications [28], we sought to examine the role of ATF4 in this process. Treatment with the proteasome inhibitor MG132 resulted in a higher induction of LATS1 expression in ATF4-deficient than proficient HT1080 cells and MEFs in response to $\mathrm{H}_{2} \mathrm{O}_{2}$ treatment (Figure 4B, 4C). This finding implicated ATF4 in the stabilization of LATS1 protein under oxidative stress.

\section{ATF4 inhibits NEDD4.2 and WWP1 expression under oxidative stress}

Several studies established that members of the neural precursor cell expressed developmentally downregulated 4 (NEDD4) family of the E3 ubiquitin-protein ligases play key roles in LATS1 destabilization [29, 30]. We observed that among the different NEED4 family members NEDD4.2 and WW domain containing E3 ligase 1 (WWP1) mRNA levels were substantially increased in ATF4-deficient compared to proficient HT1080 cells in response to $\mathrm{H}_{2} \mathrm{O}_{2}$ treatment (Figure $5 \mathrm{~A}$ ). We also observed that NEED4.1 and WWP2 mRNA levels were not induced in ATF4-deficient HT1080 cells under oxidative stress (Figure 5A). Moreover, NEDD4.2 mRNA levels were upregulated in ATF4 KO MEFs as opposed to WWP1 mRNA levels, which were marginally increased by the loss of ATF4 (Figure 5B). Immunoblot analyses showed the downregulation of NEDD4.2 and WWP1 in ATF4proficient but not deficient HT1080 cells in response to $\mathrm{H}_{2} \mathrm{O}_{2}$ treatment (Figure 5C). It was of interest that ATF4 mediated a stronger inhibitory effect on the protein than the mRNA levels of WWP1 suggesting that ATF4 may also inhibit WWP1 expression at the translational and/ or post-translational level. These data revealed the ability of ATF4 to inhibit the expression of E3 ubiquitin ligases involved in LATS1 degradation under oxidative stress.

\section{LATS1 promotes the induction of cell death under oxidative stress}

Recent studies showed that induction of the HIPPO pathway and YAP inactivation by oxidative stress promotes human cardiomyocyte death through LATS2 activation [15, 16]. Similarly, we found that LATS1 downregulation by shRNA substantially decreased the susceptibility of HT1080 cells to death by $\mathrm{H}_{2} \mathrm{O}_{2}$ (Figure 6A, 6B). Also, immortalized MEFs from LATS1 KO mice exhibited an increased resistance to $\mathrm{H}_{2} \mathrm{O}_{2}$-mediated death compared to their isogenic LATS1 WT counterparts (Figure 6C, 6D). We observed that LATS1 inactivation in HT1080 cells mitigated the induction of eIF $2 \alpha \mathrm{P}$ in response to $\mathrm{H}_{2} \mathrm{O}_{2}$-treatment (Figure 6A). On the other hand, LATS1 depletion in MEFs increased the basal levels of eIF $2 \alpha \mathrm{P}$ but decreased its further induction upon 
(A)

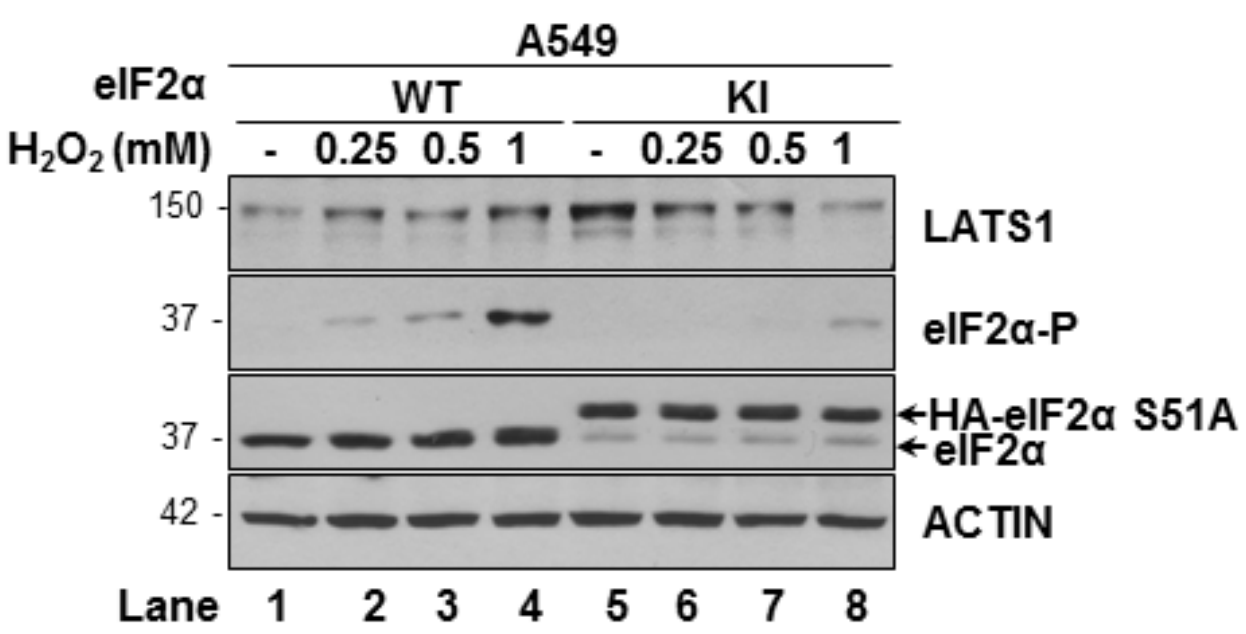

(B)

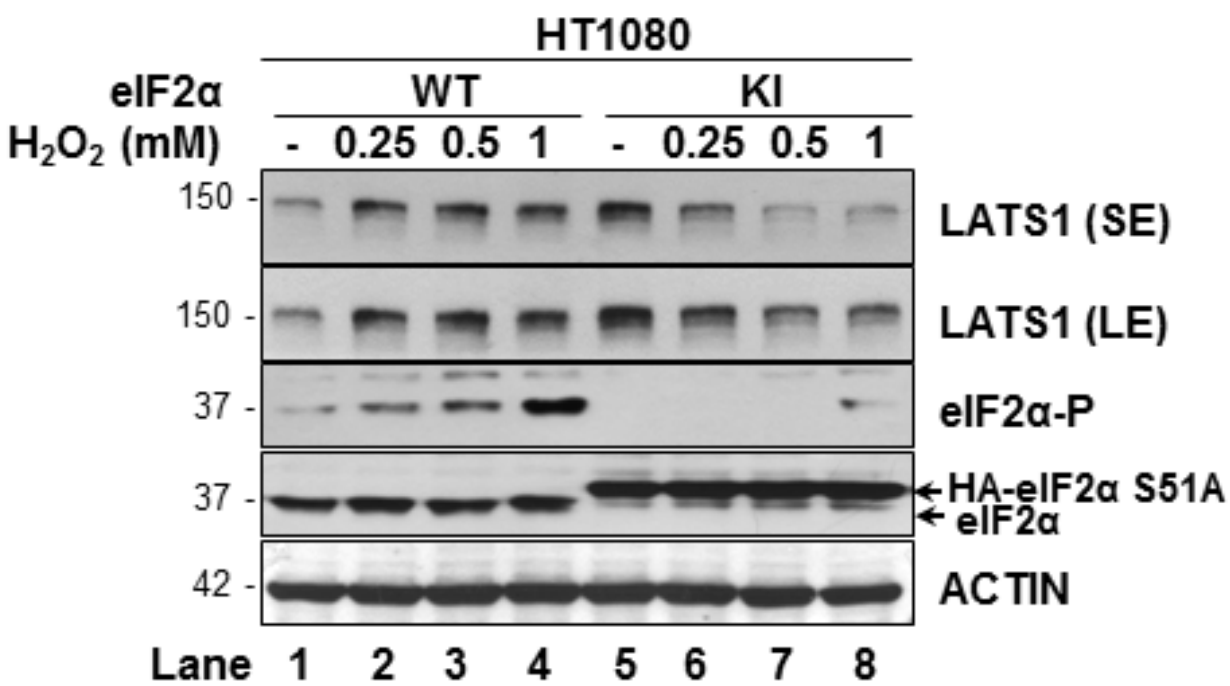

(C)

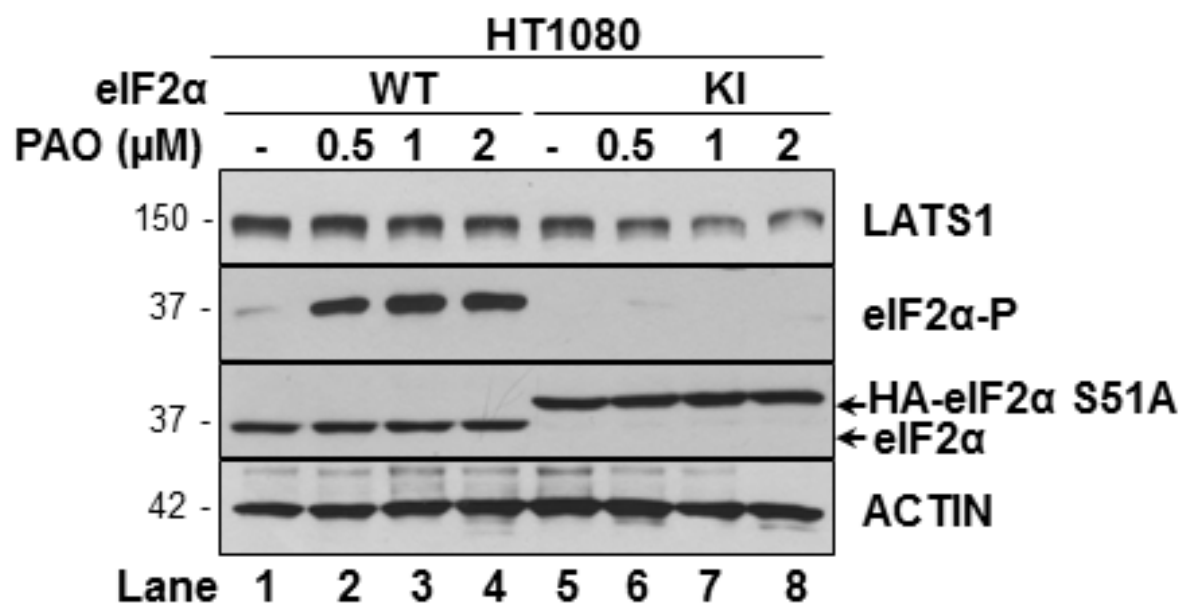

Figure 2: eIF2 $\alpha$ P facilitates LATS1 expression in tumor cells under oxidative stress. A549 cells A. and HT1080 cells B., C. that were either proficient (wild type; WT) or deficient for eIF $2 \alpha \mathrm{P}\left(\right.$ knock-in; KI) were exposed to the indicated concentrations of $\mathrm{H}_{2} \mathrm{O}_{2}$ for $2 \mathrm{~h}$ A.-B. as well as the pro-oxidant drug PAO for $15 \mathrm{~min}$ C.. Protein extracts $(50 \mu \mathrm{g})$ were immunoblotted for the indicated proteins. The approximate molecular size of the proteins as well as the position of HA-eIF $2 \alpha$ S51A and endogenous eIF $2 \alpha$ in the polyacrylamide gels is indicated. 
(A)

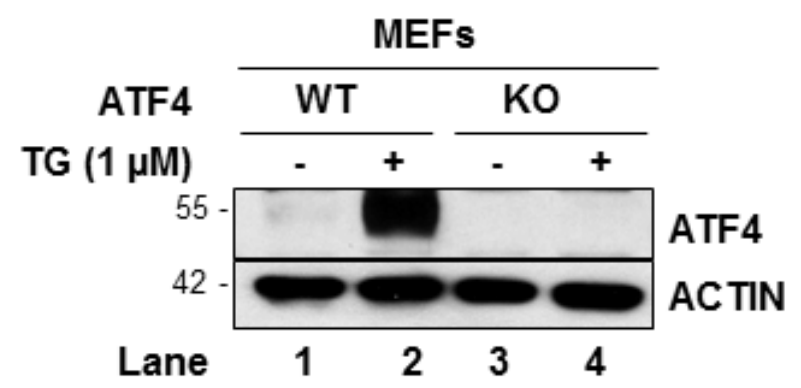

(B)

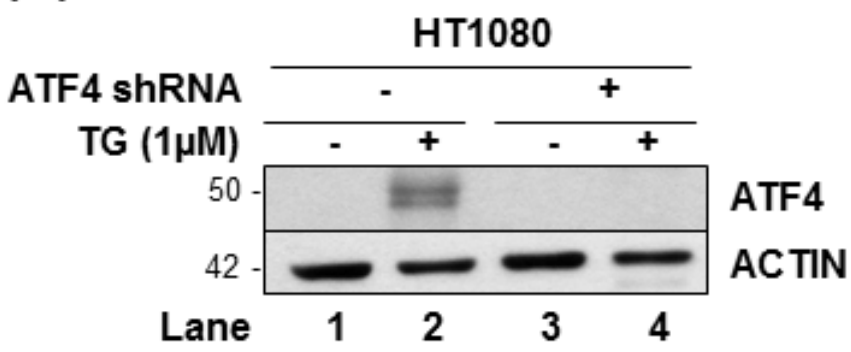

(C)

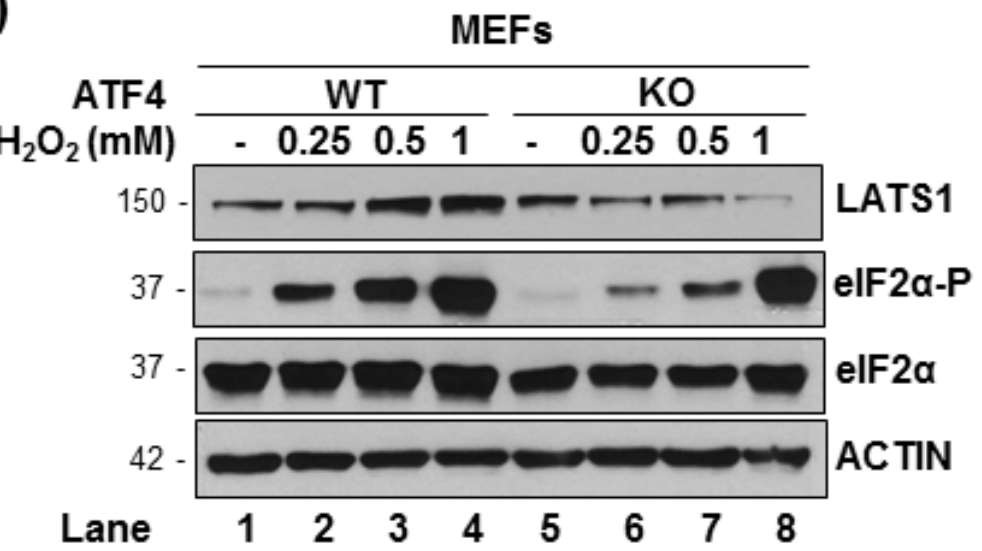

(D)

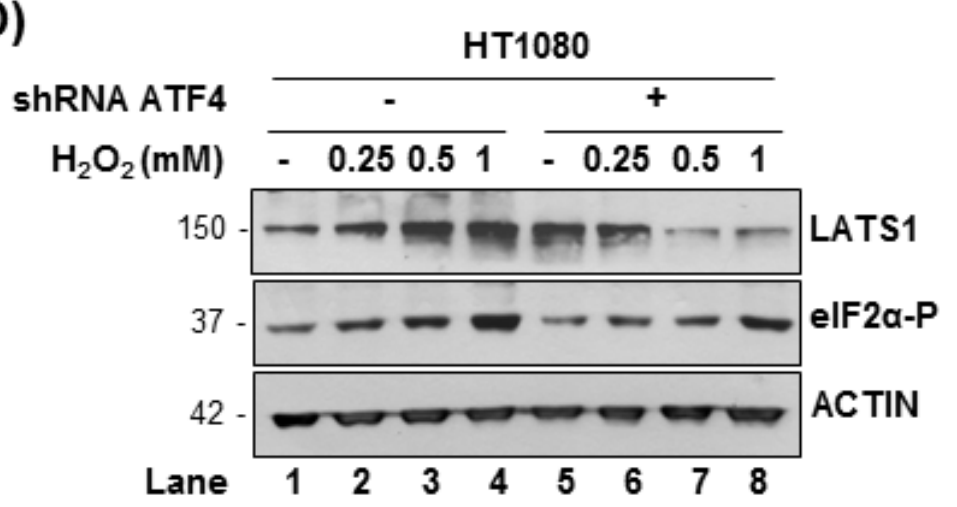

(E)

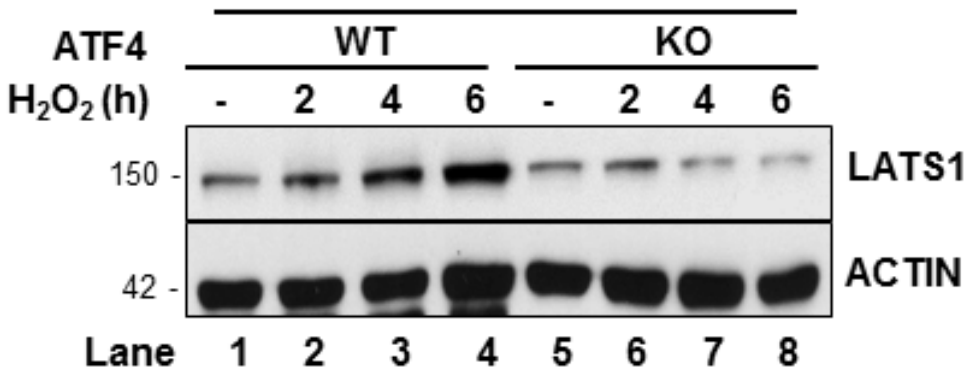

Figure 3: ATF4 promotes LATS1 expression under pro-oxidant conditions: A., B. Immortalized MEFs containing (WT) or lacking ATF4 (knockout; KO) as well as HT1080 cells lacking (-) or expressing ATF4 shRNA (+) were subjected to $1 \mu$ M thapsigargin (TG) for 2h. C., D. ATF4 WT and KO MEFs as well as HT1080 cells lacking or expressing ATF4 shRNA were treated with the indicated amounts of $\mathrm{H}_{2} \mathrm{O}_{2}$ for $2 \mathrm{~h}$. E. ATF4 WT and KO MEFs were treated with $0.5 \mathrm{mM} \mathrm{H}_{2} \mathrm{O}_{2}$ for the indicated time points. A.-E. Protein extracts (50 $\mu \mathrm{g}$ ) were immunoblotted for the indicated proteins. The approximate molecular size of the proteins in the polyacrylamide gels is indicated. 
(A)

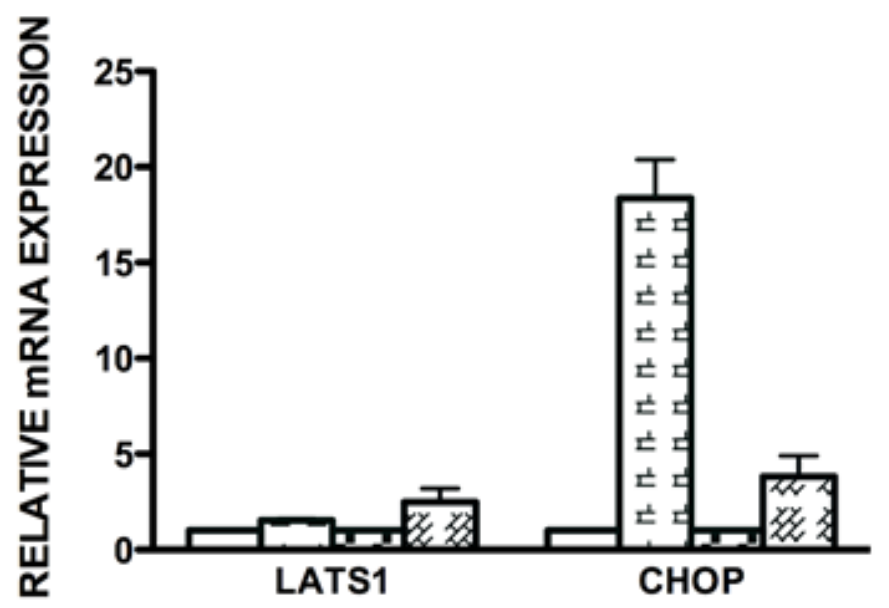

(B)

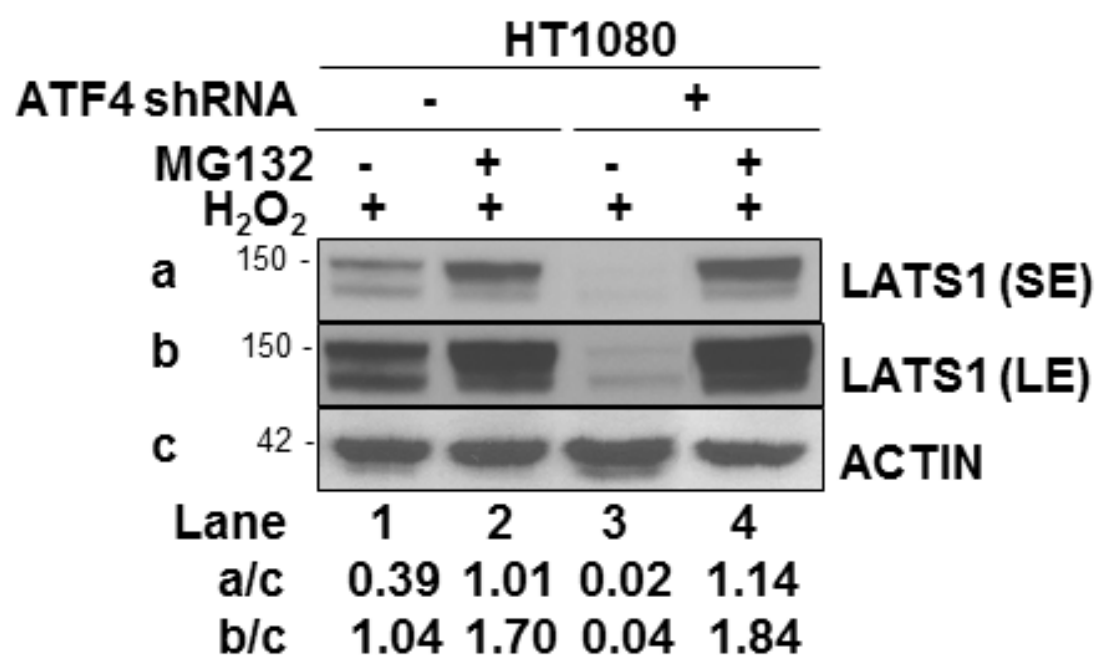

(C)

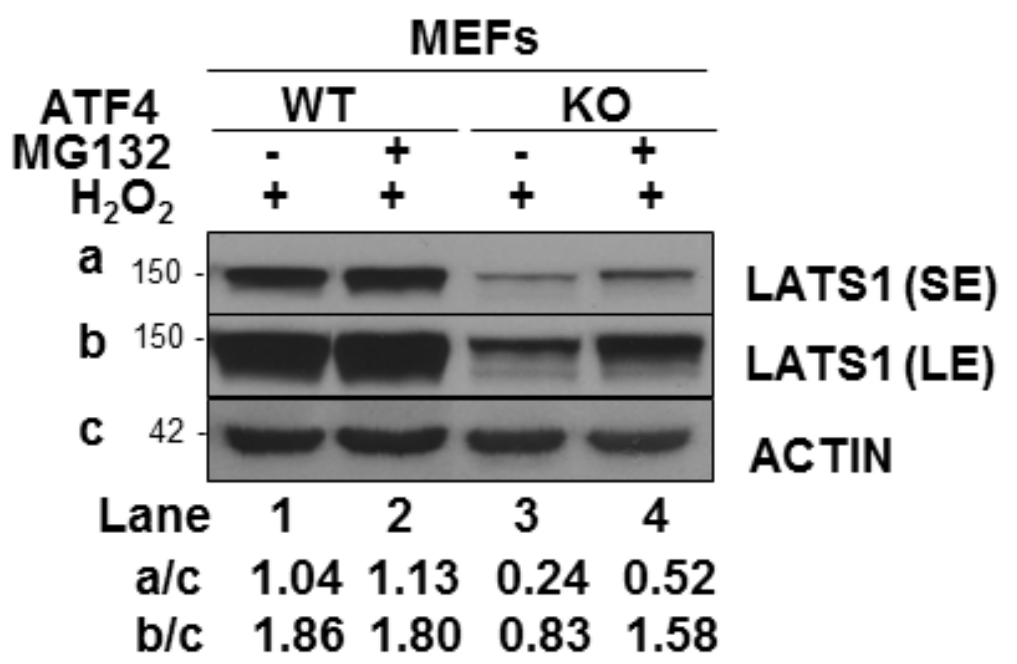

Figure 4: ATF4 mediates LATS1 stabilization under oxidative stress. A. Detection of LATS1 and CHOP mRNAs by qPCR in ATF4-proficient and deficient (shRNA expressing) HT1080 cells exposed to $0.5 \mathrm{mM} \mathrm{H}_{2} \mathrm{O}_{2}$ for 8 h. B., C. ATF4-proficient or deficient (shRNA expressing) HT1080 cells as well as ATF4 WT or KO MEFs were untreated or pre-treated with $25 \mu \mathrm{M}$ of MG132 for $1 \mathrm{~h}$ followed by treatment with $0.25 \mathrm{mM} \mathrm{H}_{2} \mathrm{O}_{2}$ in the absence or presence of MG132 for 4 h. B., C. Protein extracts $(50 \mu \mathrm{g})$ were immunoblotted for the indicated proteins. The approximate molecular size of the proteins in the polyacrylamide gels is indicated. The ratios of quantified bands for each lane are indicated. SE, short blot exposure; LE, long blot exposure. 
oxidative stress compared to LATS1-proficient MEFs (Figure 6C). The effect of LATS1 inactivation on eIF2 $\alpha \mathrm{P}$ was similar to that observed with LATS1 downregulation in ATF4-deficient MEFs indicating the presence of a LATS1-orchestrated feedback loop leading to increased eIF2 $\alpha \mathrm{P}$ and LATS1 stabilization under oxidative stress (Figure 3C, 3D). Furthermore, ATF4 KO MEFs were substantially resistant to death to $\mathrm{H}_{2} \mathrm{O}_{2}$ compared to ATF4 WT MEFs supporting the notion that ATF4 and LATS1 act in the same pathway to induce cell death under oxidative stress (Figure 6E).

\section{DISCUSSION}

Previous studies by our group established that increased eIF $2 \alpha \mathrm{P}$ by PERK and GCN2 under oxidative stress mediates the induction of pro-survival responses that depend on AKT activation [18, 21]. AKT exhibits pro-survival functions but its activation under conditions
(A)

(B)

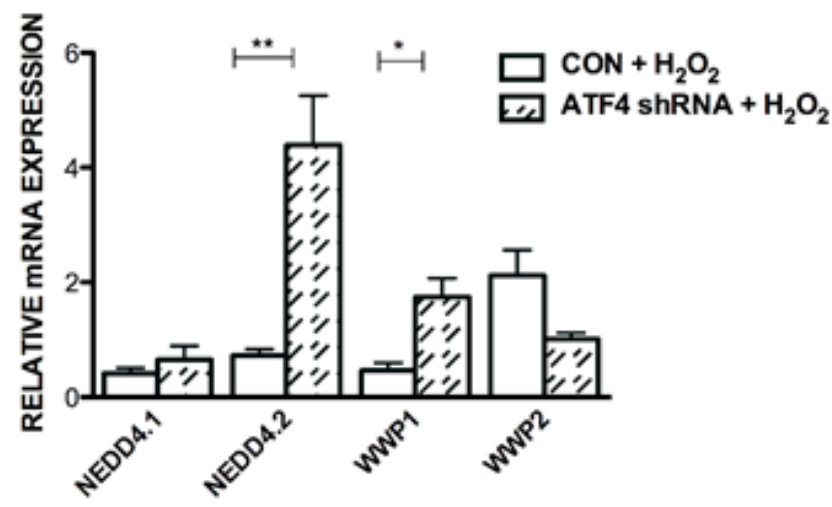

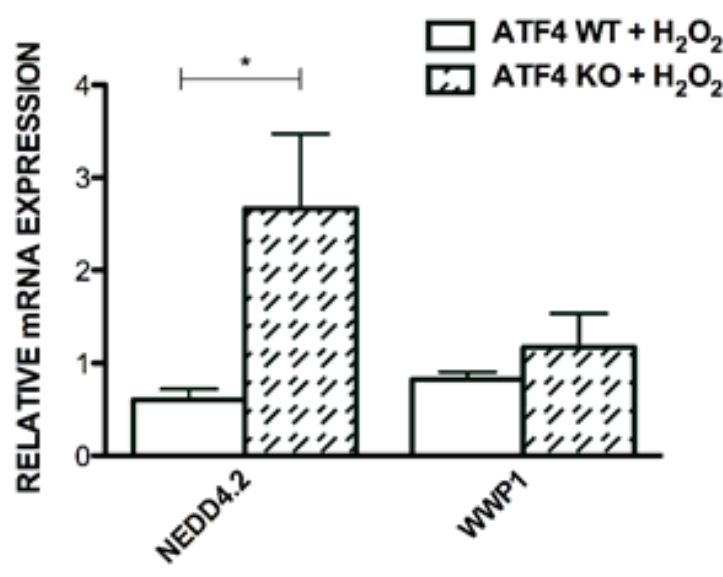

(C)

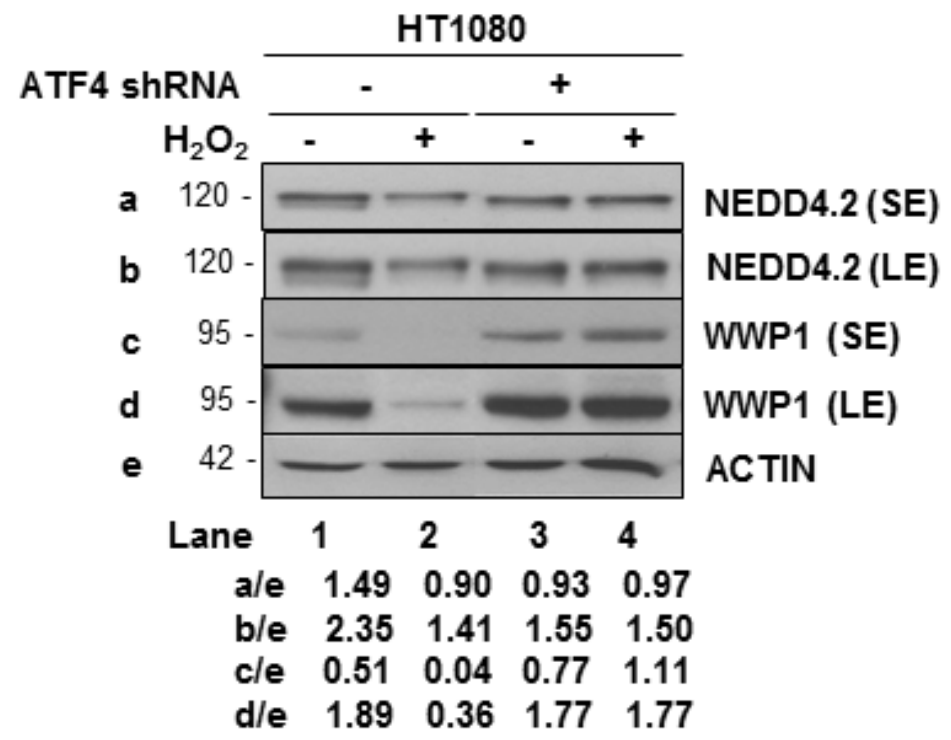

Figure 5: ATF4 decreases NEDD4 and WWP1 expression under oxidative stress. A., B. Quantification of mRNA levels by qPCR of the indicated E3 ubiquitin ligase genes in HT1080 cells A. or MEFs B. subjected to $\mathrm{H}_{2} \mathrm{O}_{2}$ treatment after normalization to mRNA levels in untreated cells. Values represent arithmetical mean \pm SE for individual gene from 3 independent experiments. $* P<0.05 ; * * P$ $<0.01$ C. ATF4-proficient and ATF4 shRNA-expressing HT1080 cells were left untreated or treated with $0.5 \mathrm{mM} \mathrm{H}_{2} \mathrm{O}_{2}$ for $4 \mathrm{~h}$. Protein extracts $(50 \mu \mathrm{g})$ were immunoblotted for the indicated proteins. The approximate molecular size of the proteins in the polyacrylamide gels is indicated. The ratios of protein intensities for each lane are indicated. SE, short exposure of the blot; LE, long exposure of the blot. 
(A)

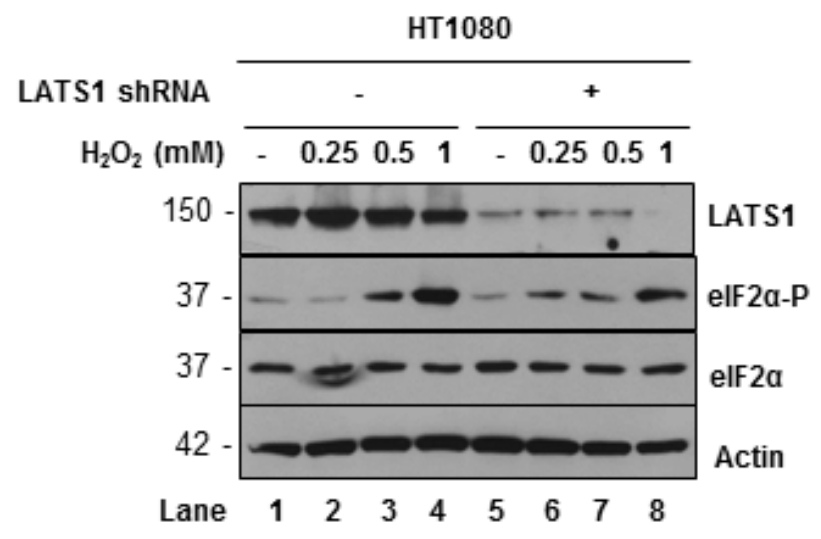

(C)

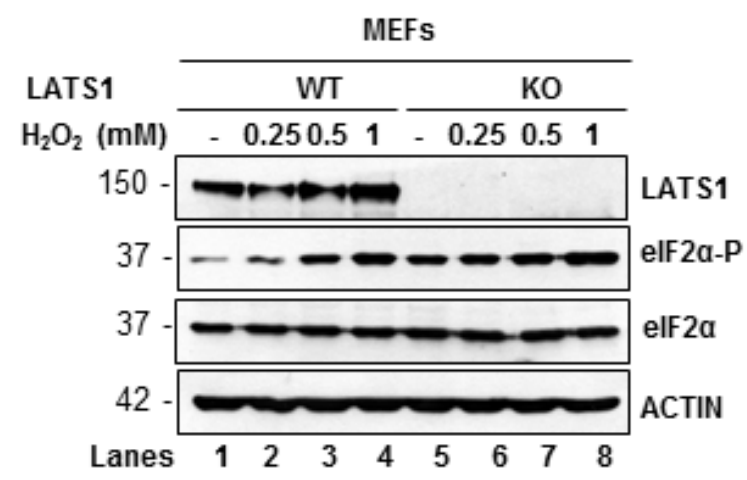

(B)

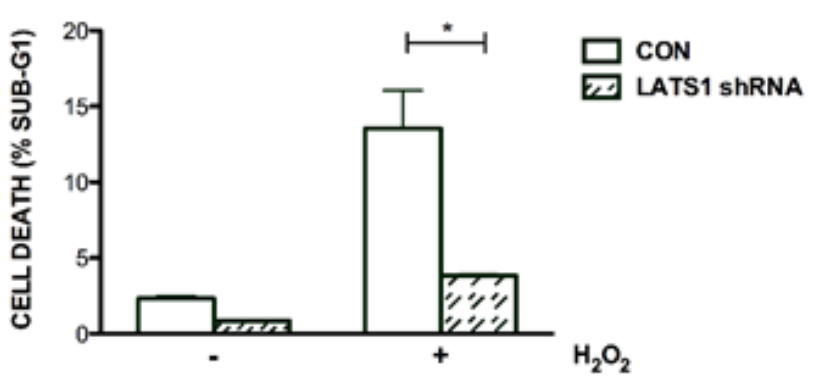

(E)

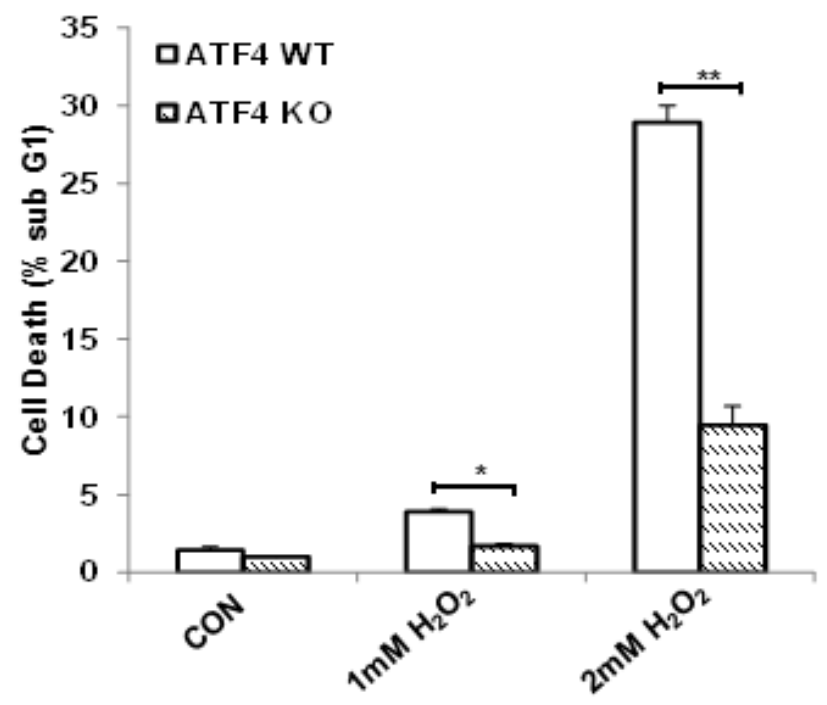

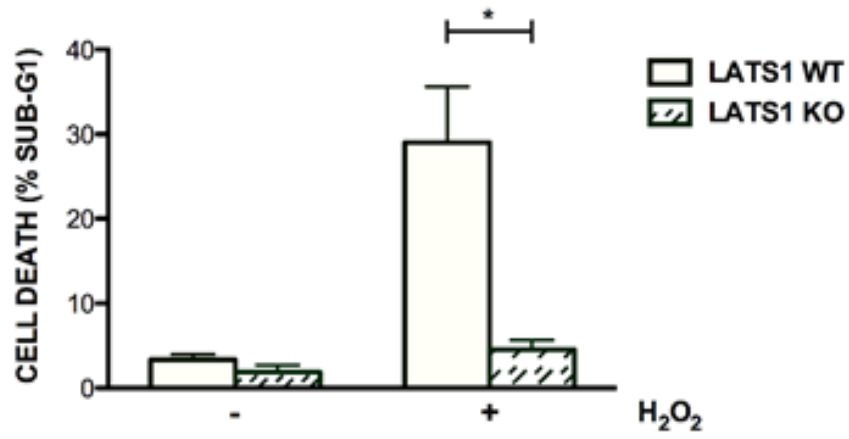

Figure 6: LATS1 promotes cell death in response to oxidative stress. LATS1-proficient and LATS1 shRNA-expressing HT1080 cells A. or LATS1 KO MEFs B. were subjected to treatments with the indicated concentrations of $\mathrm{H}_{2} \mathrm{O}_{2}$ for 2 h. A., C. Protein extracts (50 $\mu \mathrm{g}$ ) were immunoblotted for the indicated proteins. The approximate molecular size of the proteins in the polyacrylamide gels is indicated. B., D. LATS1-proficient and deficient HT1080 cells B. as well as LATS1 WT and KO MEFs D. were exposed to $1 \mathrm{mM} \mathrm{H}_{2} \mathrm{O}_{2}$ for $8 \mathrm{~h}$. E. ATF4 WT and KO MEFs were subjected to treatments with the indicated concentrations of $\mathrm{H}_{2} \mathrm{O}_{2}$ for 8 h. B.-E. Cell death was assessed by the percentage of cells in the sub- $\mathrm{G}_{1}$ population by propidium iodide staining and FACS analysis. Values represent the arithmetic mean \pm SE from 3 independent experiments. ${ }^{*} P<0.05$; ${ }^{*} P<0.01$. 
of excessive oxidative stress can also lead to induction of either premature senescence or cell death [31], both of which are antagonized by eIF $2 \alpha \mathrm{P}[18,32]$. Thus, eIF $2 \alpha \mathrm{P}$ promotes the pro-survival and inhibits the pro-death functions of AKT in cells subjected to oxidative stress [19, 32]. The ability of eIF $2 \alpha \mathrm{P}$ to mediate LATS1 stabilization, which promotes death under oxidative stress, indicates the presence of a pathway that counterbalances the prosurvival effects of eIF $2 \alpha \mathrm{P}$ in cells exposed to oxidative insults.

ATF4 mediates the expression of genes involved in amino acid import, glutathione biosynthesis, and resistance to oxidative stress [21]. Also, ATF4 hyper-activation has been implicated in the upregulation of protein synthesis, ATP depletion and increased oxidative stress leading to cell death $[23,33]$. Herein, we demonstrate that the prodeath effects of ATF4 under oxidative stress are linked to LATS1 stabilization and activation of the HIPPO pathway (Figure 7). In cells subjected to oxidative stress, ATF4 suppresses the expression of the E3 ubiquitin ligases NEDD4.2 and WWP1, both of which target LATS1 for degradation (Figure 5) [29, 30]. LATS1 and other components of the HIPPO pathway are under the control of E3 ubiquitin ligases of the NEDD4 family including NEDD4.1, NEDD4.2, ITCH and WWP1 that can determine the activation of the pathway in response to different environmental cues [29, 30, 34-37]. The WW domains of the E3 ubiquitin ligases mediate an interaction with the PPxY motif of LATS1 [38], which plays a key role in LATS1 degradation and increased YAP

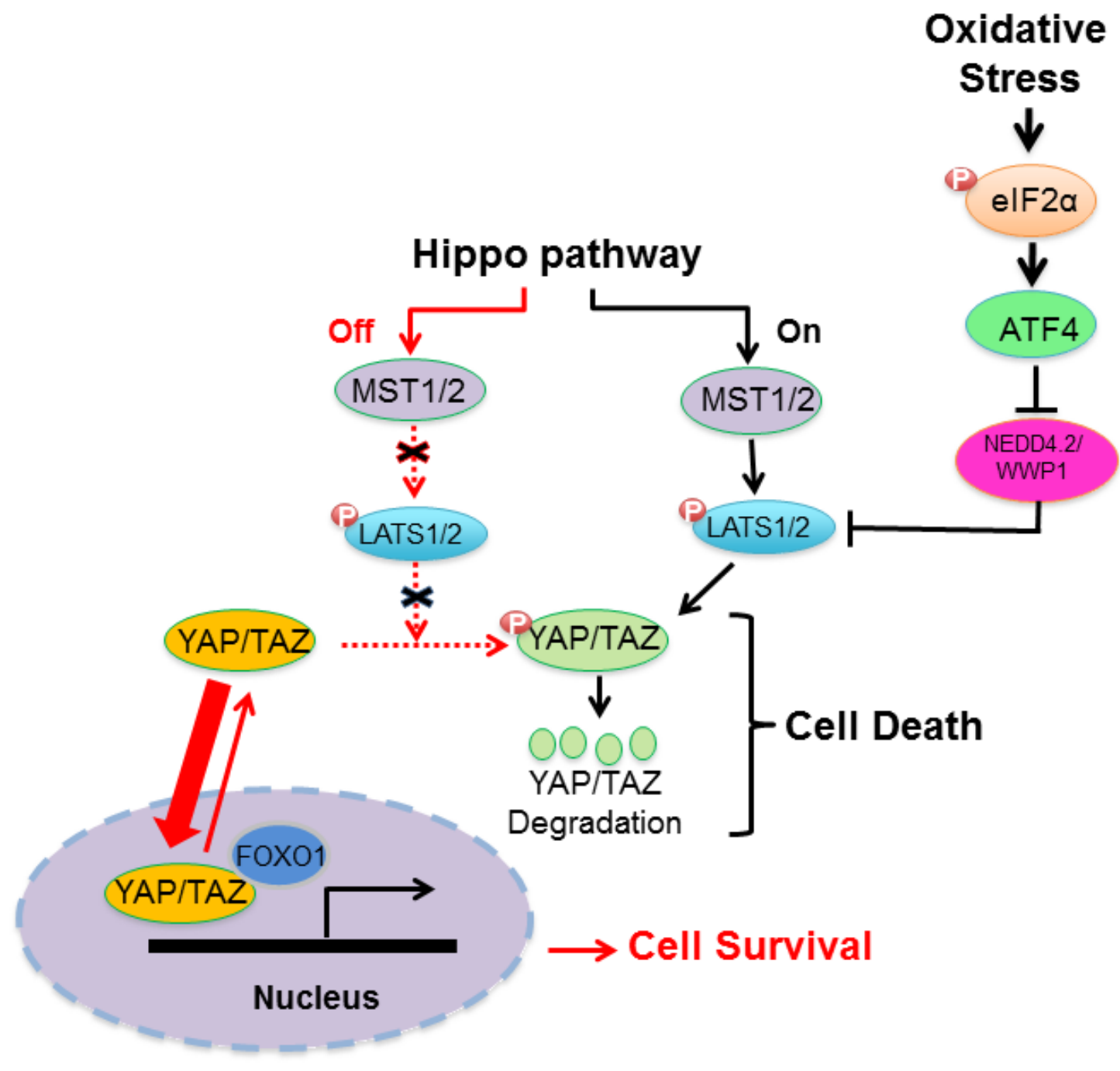

Figure 7: Schematic representation of regulation of HIPPO pathway by the eIF2 $\alpha$ P-ATF4 arm under oxidative stress. Induction of eIF $2 \alpha \mathrm{P}$ in cells subjected to oxidative stress leads to ATF4 upregulation at the translational level, which in turn inhibits the expression of E3 ubiquitin ligases NEDD4.2 and WWP1 that target LATS1 for degradation [29, 30]. LATS1 stabilization results in the phosphorylation and cytoplasmic sequestration of YAP/TAZ, which impairs YAP/TAZ-dependent expression of genes involved in cell survival and proliferation. Interaction of YAP/TAZ with FOXO1 has been demonstrated to play a key role in the induction of anti-oxidant genes and cell survival under oxidative stress [16]. 
transcriptional activity $[29,30,35]$. Our data show that ATF4 inhibits NEDD4.2 and WWP1 but not NEDD4.1 and $W W P 2$ mRNA levels indicating its role in the inhibition of specific E3 ubiquitin ligases under oxidative stress (Figure 5). ATF4 appears to function as a transcriptional repressor of NEDD4.2 and WWP1, which is line with its ability to inhibit the expression of several genes in stress-regulated genes including members of the NEDD4 family [23]. Our findings are in line with recent studies demonstrating that HIPPO activation and YAP inactivation by oxidative stress promotes the death of human cardiomyocytes through LATS2 activation $[15,16]$. The ability of the HIPPO pathway to cause death under oxidative stress has been attributed to the inactivation of YAP and inhibition of expression of anti-oxidant genes mediated by the interaction of YAP with FOXO1 [16]. Thus, HIPPO pathway activation downstream of ATF4 contributes to cell death and may be an important determinant of the cell fate decisions of ATF4 in cells under oxidative stress (Figure 7).

A recent study indicated the presence of a crosstalk between eIF $2 \alpha \mathrm{P}$ and HIPPO signaling in cells subjected to ER stress [39]. Specifically, the PERK-eIF2 $\alpha$ P-ATF4 arm cooperates with YAP to increase cell survival under transient ER stress [39]. However, prolonged ER stress activates the HIPPO pathway, which promotes the expression of the growth arrest and DNA damage-inducible protein 34 (GADD34) subunit of protein phosphatase 1 (PP1) resulting in eIF $2 \alpha \mathrm{P}$ de-phosphorylation and increased susceptibility of stressed cells to death [39]. The functional crosstalk between the PERK-eIF2 $\alpha \mathrm{P}-\mathrm{ATF} 4$ and HIPPO pathways under ER stress was found to be implicated in liver size and tumorigenesis [39]. However, the effects elicited by the activation of HIPPO pathway under ER stress may not depend on LATS1/2 inasmuch as other kinases downstream of MST1 and 2 such as the nuclear dbf2-related (NDR) kinase have been implicated in YAP phosphorylation and inhibition of liver and colon cancer $[40,41]$. Also, ER stress induces the expression of seven in absentia homolog 2 (SIAH2), a ubiquitin ligase that has been implicated in ATF4 stabilization and induction of cell death [42]. SIAH2 was shown to lead to LATS2 destabilization and YAP activation in hypoxic cells [43], an effect that provides a tentative connection between ATF4 and HIPPO pathway in stressed cells in the tumor microenvironment. Our data show that, unlike ER stress, the eIF $2 \alpha \mathrm{P}-\mathrm{ATF} 4$ arm contributes to HIPPO activation and cell death. Also, different from ER stress, LATS1 stabilization does not decrease but rather increases eIF $2 \alpha \mathrm{P}$ indicating a positive effect of HIPPO activation on eIF $2 \alpha \mathrm{P}$ under oxidative stress (Figure 6). Collectively, the findings indicate that the eIF $2 \alpha \mathrm{P}-\mathrm{ATF} 4$ arm mediates distinct effects on the HIPPO pathway in response to different forms of stress.

Previous work demonstrated that increased ROS levels cause the activation of protein kinase $\mathrm{C}$ delta
(PKC $\delta$ ) leading to downregulation of LATS1 and impaired cytokinesis [44]. A recent study indicated that inactivation of PKR causes a defect in cytokinesis raising the intriguing hypothesis that such an effect of the eIF $2 \alpha$ kinase could be mediated, at least in part, by LATS1 downregulation [45]. Blockade of cytokinesis is thought to act as barrier to cellular immortalization ensuring stable cell-cycle arrest in senescent cells [45], an effect that could account for the inability of eIF $2 \alpha \mathrm{P}$ - and ATF4-deficient cells to bypass senescence and undergo oncogenic transformation [19, 46].

There has been growing and strong evidence to suggest that HIPPO is a tumor suppressor pathway. LATS1 KO mice develop fibrosarcomas by 4-10 months of age whereas disruption of other key components of the HIPPO pathway has led to the development of many tumor forms in mice including hepatocellular carcinoma, Schwannoma, squamous cell carcinoma or malignant mesothelioma [47, 48]. On the other hand, YAP/TAZ exhibits oncogenic properties and its hyper-activation is observed in many forms of human cancers [48]. Studies aimed at targeting the HIPPO pathway in cancer are still in infancy; pharmacological inhibition of YAP/TAZTEAD complex formation by drugs like verteporfin is thought to be an efficient way to activate HIPPO signaling and is an emerging anti-tumor treatment with promising results in tissue culture assays and mouse models of cancer $[49,50]$. On the other hand, eIF $2 \alpha \mathrm{P}$ is intimately involved in the survival and adaptation of cells exposed to oncogenic insults and promotes tumor survival in response to chemotherapeutic drugs or radiotherapy [6, 51]. The functional interplay between the eIF $2 \alpha \mathrm{P}-\mathrm{ATF} 4$ and HIPPO pathways under oxidative stress may provide a potential nodal point for anti-tumor intervention with prooxidant therapies. For example, pro-oxidant therapies may simultaneously induce the pro-survival effects of eIF $2 \alpha \mathrm{P}$ through the activation of AKT and pro-death effects of ATF4 via LATS1 stabilization and HIPPO activation. Pharmacological manipulation of the two opposing pathways may improve anti-tumor response to pro-oxidant therapies and prove an effective means to treat cancers with high content of ROS.

\section{MATERIALS AND METHODS}

\section{Cell culture and treatments}

Primary as well as immortalized eIF $2 \alpha \mathrm{P}$-proficient or deficient MEFs, IMR90, BJ-hTERT, HT1080, and A549 cells were generated and maintained as described previously $[18,19]$. ATF4 KO MEFs as well as HT1080 cells expressing ATF4 shATF4 were established as previously described [18]. LATS1 KO MEFs were previously reported [52]. The shRNA-mediated 
knockdown of LATS1 in HT1080 cells was performed with as previously described targeting vector [53]. Cells were cultured in Dulbecco modified Eagle medium (DMEM; Wisent) supplemented with 10\% fetal bovine serum (FBS; Gibco), antibiotics (100 U/ml of penicillinstreptomycin; Gibco) and $2.5 \mu \mathrm{g} / \mathrm{ml}$ of puromycin (Sigma). $\mathrm{H}_{2} \mathrm{O}_{2}$ was purchased from Bioshop, Canada; thapsigargin, trolox, phenylarsine oxide (PAO) and propidium iodide were obtained from Sigma; MG132 was purchased from Enzo Life Sciences. In control treatments, an equivalent volume of the solvent of each drug was added in culture.

\section{Flow cytometry analysis}

Cells were subjected to propidium iodide staining and FACScan analysis based on a previously described protocol [18]. FACS was performed with BD FACScalibur and the data was analyzed using the FlowJo software (Tree Star inc).

\section{Western blot analysis}

Protein extraction, quantification and immunoblotting were performed as previously described $[18,19]$. The primary antibodies rabbit monoclonal against phosphorylated eIF2 $\alpha$ at S51 (Novus Biologicals), mouse monoclonal against eIF2 $\alpha$ (Cell Signaling Tech.) rabbit polyclonal against YAP phosphorylated at S127 (Cell Signaling Tech.), rabbit monoclonal against YAP (Cell Signaling), rabbit monoclonal against LATS1 (Cell Signaling Tech.), mouse monoclonal antibody against actin (Clone $\mathrm{C} 4$, ICN Biomedicals Inc) rabbit monoclonal against NEDD4.2 (Abcam), rabbit polyclonal against WWP1 or ATF4 (Proteintech) were used. All antibodies were used at a final concentration of $0.1-1$ $\mu \mathrm{g} / \mathrm{ml}$. Following incubation with the indicated primary antibodies, membranes were probed with either anti-mouse or anti-rabbit IgG antibodies conjugated to horseradish peroxidise (HRP) (Mandel Scientific). Proteins were visualized with the enhanced chemiluminescence (ECL) reagent (Thermo Scientific) detection system according to the manufacturer's instructions. Quantification of bands in linear range of exposure was performed by densitometry using Scion image software (Frederick, Maryland, USA).

\section{RNA extraction, reverse transcriptase assay and real-time PCR}

RNA was extracted using TRIzol reagent (Invitrogen) according to manufacturer's instructions. This was followed by cDNA preparation using the superscript III RNase H-reverse transcriptase (Invitrogen) as provided in the manufacturer's manual. Real-time PCR was performed on a ThermoCycler instrument
(Eppendorf) using the SensiFast SYBR Green kit (FroggaBio). The following oligonucleotides were used for the amplification:

Human ACTIN (Forward

5'-CAGCAGATGTGGATCAGCAAG-3'; Reverse

5'-GCATTTGCGGTGGACGAT-3'); Human LATS1

(Forward 5'-GGCTTCAGATGGACACACGAT-3'

; Reverse 5'-CCACATCGACAGCTTGAGGG-3'); Human NEDD4.1 (Forward

5'-CACATCTCGGGTGCCTATGA-3'; Reverse

5'-TCAGGAGTACCCCACTGTTCA-3');

Human NEDD4.2 (Forward

5'-CAATGGGGCAGTCCTGAGAA-3'; Reverse

5'-TTCCACGGCCATGAGAAGTT-3'); Human WWP1

(Forward 5'-TTGCTGAGCTCATGGGAAGT-3';

Reverse 5'-TGGTGGTAGATCCAAGCGAT-3');

Human WWP2 (Forward 5'-

CGTCAAGAACTCAGGCCACA-3'; Reverse 3'CAACGGAAGGTTCTTCGGGA-3'); Human CHOP (Forward 5'-GAGCTGGAACCTGAGGAGAGA-3'; Reverse 5'-TGCAGTTGGATCAGTCTGCTT-3'); Mouse NEDD4.1 (Forward 5'-GGGGCAGTCCCGAAAAACTA-3';

Reverse 5'-GGATTGTGGTCCATTCGAGC-3'); Mouse NEDD4.2 (Forward 5'-GGGGCAGTCCCGAAAAACTA-3'; Reverse 5'-CTTGAGCGTTTTCCACAGCC-3'); Mouse WWP1 (Forward 5'-TTGCTGAGCTCATGGGAAGT-3'; Reverse 5'-TGGTGGTAGATCCAAGCGAT-3'); Mouse CHOP (Forward 5'-AGTTATCTTGAGCCTAACACGTC-3'; Reverse 5'-CACTTCCTTCTGGAACACTCTCTC-3')

\section{Statistical analysis}

Statistical analysis was performed using Graph Pad Prism 5.0. Error bars represent standard error (SE). Significance in differences between arrays of data tested was determined using two-tailed Student ' $t$ ' test.

\section{ACKNOWLEDGMENTS}

We thank J. Zhang for human LATS1 shRNAexpressing vector. The work was supported by funds form the Canadian Cancer Society Research Institute (CCSRI no. 700886) and the Canadian Institutes of Health Research (CIHR no. 38160) to AEK. AIP was recipient of a CIHR Frederick Banting Charles Best Canadian Graduate Scholarship, a CIHR Michael Smith Foreign supplement award and a CIHR-funded McGill Chemical Biology post-doctoral award.

\section{CONFLICTS OF INTEREST}

The authors have no conflict of interest to declare. 


\section{Editorial note}

This paper has been accepted based in part on peerreview conducted by another journal and the authors' response and revisions as well as expedited peer-review in Oncotarget.

\section{REFERENCES}

1. Yu FX and Guan KL. The Hippo pathway: regulators and regulations. Genes Dev. 2013; 27:355-371.

2. Zhao B, Li L, Tumaneng K, Wang CY and Guan KL. A coordinated phosphorylation by Lats and CK1 regulates YAP stability through SCF(beta-TRCP). Genes Dev. 2010; 24:72-85.

3. Moroishi T, Hansen CG and Guan KL. The emerging roles of YAP and TAZ in cancer. Nat Rev Cancer. 2015; 15:7379.

4. Holcik M and Sonenberg N. Translational control in stress and apoptosis. Nat Rev Mol Cell Biol. 2005; 6:318-327.

5. Wek RC, Jiang HY and Anthony TG. Coping with stress: eIF2 kinases and translational control. Biochem Soc Trans. 2006; 34:7-11.

6. Koromilas AE. Roles of the translation initiation factor eIF2alpha serine 51 phosphorylation in cancer formation and treatment. Biochim Biophys Acta. 2015; 1849:871-880.

7. Sonenberg N and Hinnebusch AG. Regulation of translation initiation in eukaryotes: mechanisms and biological targets. Cell. 2009; 136:731-745.

8. Dever TE, Feng L, Wek RC, Cigan AM, Donahue TF and Hinnebusch AG. Phosphorylation of initiation factor 2 alpha by protein kinase GCN2 mediates gene-specific translational control of GCN4 in yeast. Cell. 1992; 68:585596.

9. Zhou D, Palam LR, Jiang L, Narasimhan J, Staschke KA and Wek RC. Phosphorylation of eIF2 directs ATF5 translational control in response to diverse stress conditions. J Biol Chem. 2008; 283:7064-7073.

10. Vattem KM and Wek RC. Reinitiation involving upstream ORFs regulates ATF4 mRNA translation in mammalian cells. Proc Natl Acad Sci U S A. 2004; 101:11269-11274.

11. Holmstrom KM and Finkel T. Cellular mechanisms and physiological consequences of redox-dependent signalling. Nat Rev Mol Cell Biol. 2014; 15:411-421.

12. Chae JS, Gil Hwang S, Lim DS and Choi EJ. Thioredoxin-1 functions as a molecular switch regulating the oxidative stress-induced activation of MST1. Free Radic Biol Med. 2012; 53:2335-2343.

13. Lehtinen MK, Yuan Z, Boag PR, Yang Y, Villen J, Becker EB, DiBacco S, de la Iglesia N, Gygi S, Blackwell TK and Bonni A. A conserved MST-FOXO signaling pathway mediates oxidative-stress responses and extends life span. Cell. 2006; 125:987-1001.
14. Xiao L, Chen D, Hu P, Wu J, Liu W, Zhao Y, Cao M, Fang Y, Bi W, Zheng Z, Ren J, Ji G, Wang Y and Yuan Z. The c-Abl-MST1 signaling pathway mediates oxidative stressinduced neuronal cell death. J Neurosci. 2011; 31:96119619.

15. Del Re DP, Yang Y, Nakano N, Cho J, Zhai P, Yamamoto T, Zhang N, Yabuta N, Nojima H, Pan D and Sadoshima J. Yes-associated protein isoform 1 (Yap1) promotes cardiomyocyte survival and growth to protect against myocardial ischemic injury. J Biol Chem. 2013; 288:39773988.

16. Shao D, Zhai P, Del Re DP, Sciarretta S, Yabuta N, Nojima H, Lim DS, Pan D and Sadoshima J. A functional interaction between Hippo-YAP signalling and FoxO1 mediates the oxidative stress response. Nat Commun. 2014; 5:3315.

17. Yamamoto S, Yang G, Zablocki D, Liu J, Hong C, Kim SJ, Soler S, Odashima M, Thaisz J, Yehia G, Molina CA, Yatani A, Vatner DE, Vatner SF and Sadoshima J. Activation of Mst1 causes dilated cardiomyopathy by stimulating apoptosis without compensatory ventricular myocyte hypertrophy. J Clin Invest. 2003; 111:1463-1474.

18. Rajesh K, Krishnamoorthy J, Kazimierczak U, Tenkerian C, Papadakis AI, Wang S, Huang S and Koromilas AE. Phosphorylation of the translation initiation factor eIF2alpha at serine 51 determines the cell fate decisions of Akt in response to oxidative stress. Cell Death Dis. 2015; 6:e1591.

19. Rajesh K, Papadakis AI, Kazimierczak U, Peidis P, Wang S, Ferbeyre G, Kaufman RJ and Koromilas AE. eIF2alpha phosphorylation bypasses premature senescence caused by oxidative stress and pro-oxidant antitumor therapies. Aging (Albany NY). 2013; 5:884-901. doi: 10.18632/ aging. 100620 .

20. Nemoto N, Udagawa $T$, Ohira $T$, Jiang L, Hirota $K$, Wilkinson CR, Bahler J, Jones N, Ohta K, Wek RC and Asano K. The roles of stress-activated Sty1 and Gen2 kinases and of the protooncoprotein homologue Int6/eIF3e in responses to endogenous oxidative stress during histidine starvation. J Mol Biol. 2010; 404:183-201.

21. Harding HP, Zhang Y, Zeng H, Novoa I, Lu PD, Calfon M, Sadri N, Yun C, Popko B, Paules R, Stojdl DF, Bell JC, Hettmann T, Leiden JM and Ron D. An integrated stress response regulates amino acid metabolism and resistance to oxidative stress. Mol Cell. 2003; 11:619-633.

22. Back SH, Scheuner D, Han J, Song B, Ribick M, Wang J, Gildersleeve RD, Pennathur S and Kaufman RJ. Translation attenuation through eIF2alpha phosphorylation prevents oxidative stress and maintains the differentiated state in beta cells. Cell Metab. 2009; 10:13-26.

23. Han J, Back SH, Hur J, Lin YH, Gildersleeve R, Shan J, Yuan CL, Krokowski D, Wang S, Hatzoglou M, Kilberg MS, Sartor MA and Kaufman RJ. ER-stress-induced transcriptional regulation increases protein synthesis 
leading to cell death. Nat Cell Biol. 2013; 15:481-490.

24. Hansen CG, Moroishi T and Guan KL. YAP and TAZ: a nexus for Hippo signaling and beyond. Trends Cell Biol. 2015; 25:499-513.

25. Forrest VJ, Kang YH, McClain DE, Robinson DH and Ramakrishnan N. Oxidative stress-induced apoptosis prevented by Trolox. Free Radic Biol Med. 1994; 16:675684.

26. Sarbassov DD and Sabatini DM. Redox regulation of the nutrient-sensitive raptor-mTOR pathway and complex. J Biol Chem. 2005; 280:39505-39509.

27. Ameri K and Harris AL. Activating transcription factor 4. Int J Biochem Cell Biol. 2008; 40:14-21.

28. He M, Zhou Z, Shah AA, Hong Y, Chen Q and Wan Y. New insights into posttranslational modifications of Hippo pathway in carcinogenesis and therapeutics. Cell Division. 2016; 11:1-10.

29. Yeung B, Ho KC and Yang X. WWP1 E3 ligase targets LATS1 for ubiquitin-mediated degradation in breast cancer cells. PLoS One. 2013; 8:e61027.

30. Salah Z, Cohen S, Itzhaki E and Aqeilan RI. NEDD4 E3 ligase inhibits the activity of the Hippo pathway by targeting LATS1 for degradation. Cell Cycle. 2013; 12:3817-3823.

31. Nogueira V, Park Y, Chen CC, Xu PZ, Chen ML, Tonic $\mathrm{I}$, Unterman $\mathrm{T}$ and Hay N. Akt determines replicative senescence and oxidative or oncogenic premature senescence and sensitizes cells to oxidative apoptosis. Cancer Cell. 2008; 14:458-470.

32. Mounir Z, Krishnamoorthy JL, Wang S, Papadopoulou B, Campbell S, Muller WJ, Hatzoglou M and Koromilas AE. Akt Determines Cell Fate Through Inhibition of the PERKeIF2 $\alpha$ Phosphorylation Pathway. Sci Signal. 2011; 4:ra62.

33. Krokowski D, Han J, Saikia M, Majumder M, Yuan CL, Guan BJ, Bevilacqua E, Bussolati O, Broer S, Arvan P, Tchorzewski M, Snider MD, Puchowicz M, Croniger CM, Kimball SR, Pan T, et al. A self-defeating anabolic program leads to beta-cell apoptosis in endoplasmic reticulum stressinduced diabetes via regulation of amino acid flux. J Biol Chem. 2013; 288:17202-17213.

34. Bae SJ, Kim M, Kim SH, Kwon YE, Lee JH, Kim J, Chung $\mathrm{CH}$, Lee WJ and Seol JH. NEDD4 controls intestinal stem cell homeostasis by regulating the Hippo signalling pathway. Nat Commun. 2015; 6:6314.

35. Ho KC, Zhou Z, She YM, Chun A, Cyr TD and Yang X. Itch E3 ubiquitin ligase regulates large tumor suppressor 1 stability [corrected]. Proc Natl Acad Sci U S A. 2011; 108:4870-4875.

36. Salah Z, Melino G and Aqeilan RI. Negative regulation of the Hippo pathway by E3 ubiquitin ligase ITCH is sufficient to promote tumorigenicity. Cancer Res. 2011; 71:20102020 .

37. Salah Z, Itzhaki E and Aqeilan RI. The ubiquitin E3 ligase ITCH enhances breast tumor progression by inhibiting the Hippo tumor suppressor pathway. Oncotarget. 2014;
5:10886-10900. doi: 10.18632/oncotarget.2540.

38. Chen HI and Sudol M. The WW domain of Yes-associated protein binds a proline-rich ligand that differs from the consensus established for Src homology 3-binding modules. Proc Natl Acad Sci U S A. 1995; 92:7819-7823.

39. Wu H, Wei L, Fan F, Ji S, Zhang S, Geng J, Hong L, Fan X, Chen Q, Tian J, Jiang M, Sun X, Jin C, Yin ZY, Liu $\mathrm{Q}$, Zhang J, et al. Integration of Hippo signalling and the unfolded protein response to restrain liver overgrowth and tumorigenesis. Nat Commun. 2015; 6:6239.

40. Zhou D, Conrad C, Xia F, Park JS, Payer B, Yin Y, Lauwers GY, Thasler W, Lee JT, Avruch J and Bardeesy N. Mst1 and Mst2 maintain hepatocyte quiescence and suppress hepatocellular carcinoma development through inactivation of the Yap1 oncogene. Cancer Cell. 2009; 16:425-438.

41. Zhang L, Tang F, Terracciano L, Hynx D, Kohler R, Bichet S, Hess D, Cron P, Hemmings Brian A, Hergovich A and Schmitz-Rohmer D. NDR Functions as a Physiological YAP1 Kinase in the Intestinal Epithelium. Current Biology. 2015; 25:296-305.

42. Scortegagna M, Kim H, Li JL, Yao H, Brill LM, Han J, Lau E, Bowtell D, Haddad G, Kaufman RJ and Ronai ZA. Fine tuning of the UPR by the ubiquitin ligases Siah1/2. PLoS Genet. 2014; 10:e1004348.

43. Ma B, Chen Y, Chen L, Cheng H, Mu C, Li J, Gao R, Zhou C, Cao L, Liu J, Zhu Y, Chen Q and Wu S. Hypoxia regulates Hippo signalling through the SIAH2 ubiquitin E3 ligase. Nat Cell Biol. 2015; 17:95-103.

44. Takahashi A, Ohtani N, Yamakoshi K, Iida S, Tahara H, Nakayama K, Nakayama KI, Ide T, Saya H and Hara E. Mitogenic signalling and the p16INK4a-Rb pathway cooperate to enforce irreversible cellular senescence. Nat Cell Biol. 2006; 8:1291-1297.

45. Kim Y, Lee JH, Park JE, Cho J, Yi H and Kim VN. PKR is activated by cellular dsRNAs during mitosis and acts as a mitotic regulator. Genes Dev. 2014; 28:1310-1322.

46. Horiguchi M, Koyanagi S, Okamoto A, Suzuki SO, Matsunaga N and Ohdo S. Stress-regulated transcription factor ATF4 promotes neoplastic transformation by suppressing expression of the INK4a/ARF cell senescence factors. Cancer Res. 2012; 72:395-401.

47. St John MA, Tao W, Fei X, Fukumoto R, Carcangiu ML, Brownstein DG, Parlow AF, McGrath J and Xu T. Mice deficient of Lats1 develop soft-tissue sarcomas, ovarian tumours and pituitary dysfunction. Nat Genet. 1999; 21:182-186.

48. Harvey KF, Zhang X and Thomas DM. The Hippo pathway and human cancer. Nat Rev Cancer. 2013; 13:246-257.

49. Johnson R and Halder G. The two faces of Hippo: targeting the Hippo pathway for regenerative medicine and cancer treatment. Nat Rev Drug Discov. 2014; 13:63-79.

50. Liu-Chittenden Y, Huang B, Shim JS, Chen Q, Lee SJ, Anders RA, Liu JO and Pan D. Genetic and pharmacological disruption of the TEAD-YAP complex 
suppresses the oncogenic activity of YAP. Genes Dev. 2012; 26:1300-1305.

51. Koromilas AE and Mounir Z. Control of oncogenesis by eIF2alpha phosphorylation: implications in PTEN and PI3K-Akt signaling and tumor treatment. Future Oncol. 2013; 9:1005-1015.

52. Chiyoda T, Sugiyama N, Shimizu T, Naoe H, Kobayashi Y, Ishizawa J, Arima Y, Tsuda H, Ito M, Kaibuchi K, Aoki D, Ishihama Y, Saya H and Kuninaka S. LATS1/WARTS phosphorylates MYPT1 to counteract PLK1 and regulate mammalian mitotic progression. J Cell Biol. 2012; 197:625641.
53. Zhang J, Smolen GA and Haber DA. Negative regulation of YAP by LATS1 underscores evolutionary conservation of the Drosophila Hippo pathway. Cancer Res. 2008; 68:27892794. 